УДК 622.276.5

ФИЗИКО-ХИМИЧЕСКИЙ МЕХАНИЗМ ДЕЙСТВИЯ МАГНИТНОЙ

ОБРАБОТКИ НА ПРОЦЕСС ОТЛОЖЕНИЯ ПАРАФИНОВ

В НАСОСНО-КОМПРЕССОРНЫХ ТРУБАХ НЕФТЯНЫХ

СКВАЖИН

\title{
PHYSICAL AND CHEMICAL MECHANISM OF MAGNETIC TREATMENT ACTION ON THE PARAFFIN DEPOSITION PROCESS IN OIL WELL PRODUCTION TUBES
}

\section{В.И. Лесин}

Институт проблем нефти и газа Российской академии наук, г. Москва, Российская Федерация

\section{Viktor I. Lesin}

Oil and Gas Research Institute of Russian Academy of Sciences, Moscow, Russian Federation

e-mail: vilesin@inbox.ru

Аннотация. Получены экспериментальные данные подтверждения ранее предложенного физического механизма защиты насоснокомпрессорных труб от отложений парафинов путем обработки нефти магнитным полем. Предложенный ранее механизм основывался на разрушении микропримесей агрегатов магнитных наноразмерных частиц оксидов железа, имеющих форму игл, на отдельные фрагменты и одиночные частицы. Эти частицы служат центрами адсорбции молекул центрами роста коллоидных частиц нефти и входят в состав отложений.

В образцах отложений были зарегистрированы магнитные частицы оксидов трехвалентного железа, имеющие форму игл длиной 50-200 нм. Магнитные частицы входят в состав агрегатов коллоидных частиц нефти, 
имеющих фрактальную структуру линейно-цепочечного типа. Показано соответствие физико-химического механизма магнитной обработки результатам практического применения. Дано обоснование геометрии и напряженности силовых линий магнитного поля, используемого в магнитных устройствах для обработки потока жидкости. Предложены методы анализа для определения перспективности применения магнитных устройств для предотвращения отложений парафинов.

Abstract. Experimental data were obtained confirming the previously proposed physical mechanism for protecting production tubes from paraffin deposits by treating oil with a magnetic field. The mechanism proposed earlier was based on the destruction of micro-admixtures of aggregates of magnetic nano sized iron oxide particles, which have the shape of needles, into separate fragments and single particles. These particles serve as adsorption centers for molecules and as growth centers for colloidal oil particles and are part of paraffin wax deposition.

Magnetic particles of $\mathrm{Fe}(3)$ iron oxides in the form of needles with a length of 50-200 $\mathrm{nm}$ were registered in the sediment samples. Magnetic particles are part of aggregates of colloidal oil particles that have a fractal structure of the linear-chain type. It is shown that the physical and chemical mechanism of magnetic processing corresponds to the results of practical application. The paper substantiates the geometry and strength of the magnetic field lines used in magnetic devices for processing liquid flow. Analytical methods are proposed to determine the prospects for using magnetic devices to prevent paraffin deposits.

Ключевые слова: нефть; насосно-компрессорная труба; отложения парафинов; магнитная коллоидная частица; магнитное поле; фрактальный агрегат коллоидных частиц нефти

Key words: oil; pump and compressor pipe; paraffin deposits; magnetic colloidal particle; magnetic field; fractal aggregate of colloidal oil particles 


\section{Введение}

Предотвращение образования отложений углеводородов на стенках насосно-компрессорных труб (НКТ) является одной из важных задач при добыче нефти с высоким содержанием высокомолекулярных компонентов. Поскольку основной углеводородный состав отложений представлен парафинами, асфальтенами и смолами, отложения принято называть асфальтосмолопарафиновыми (АСПО). Помимо перечисленных фракций АСПО содержат примеси более легких компонентов нефти, воду и неорганические частицы, в основном, оксиды металлов. Начало формирования отложений в НКТ находится над уровнем начала дегазации, поскольку выпадение в газовую фазу легких компонентов нефти снижает растворимость парафинов. АСПО обладают высокой прочностью, не разрушаются под действием сил вязкого трения, поэтому накопление отложений приводит к постепенному снижению проходного сечения НКТ, вплоть до полного перекрытия. В ходе роста во времени (старения) меняется состав и прочностные свойства АСПО: первоначальные отложения мягкие, содержат газ и легкие компоненты нефти, состаренные АСПО теряют легкие компоненты и становятся достаточно прочными, чтобы противостоять удалению с помощью растворителей, механических средств и нагрева. Особенностью АСПО является высокая прочность по всей толщине, что предполагает каркасный характер структур, образующих такие отложения $[1,2]$.

Углеводородный состав АСПО определяется составом коллоидных частиц нефти, имеющих форму мицелл, ядро которых образовано асфальтенами и смолами, а оболочка представлена парафинами, маслами и легкими фракциями [3]. Коллоидные частицы нефти за счет взаимного притяжения формируют коллективные структуры фрактального строения [4], которые представляют пористые структуры, состоящие из сотен частиц коллоидных частиц нефти и минеральных примесей. 
Одним из способов предотвращения отложений АСПО является создание в объеме нефти многочисленных центров кристаллизации парафинов. При увеличении количества центров кристаллизации выпадающие в твердую фазу компоненты нефти, распределяясь по возросшему количеству центров, образуют тонкодисперсную взвесь частиц АСПО, которая характеризуется сниженными темпами формирования отложений [1].

Известно, что коллоидные частицы оксиды железа адсорбируют на свою поверхность асфальтены, смолы и другие тяжелые углеводороды, т.е. являются центрами кристаллизации частиц, составляющих АСПО. Это позволяет использовать магнитные коллоидные частицы оксидов железа для очистки воды от загрязнений нефтью. Коллоидные магнитные частицы оксидов железа - адсорбенты, покрытые нефтью, удаляются из воды с помощью неоднородного магнитного поля, обеспечивающего перемещение и удерживание таких частиц $[5,6]$.

Результаты исследований [7] показали, что уже при общей концентрации атомов железа в воде 0,3-0,2 мг/л магнитные частицы образуют агрегаты диаметром более 2-3 мкм, которые разрушаются при протекании раствора через устройство для обработки магнитным полем (УМО). Масса атомов железа, удержанных фильтром с размерами пор 2-3 мкм, снизилась более, чем вдвое после магнитной обработки (MO) водопроводной воды. В [8,9] было установлено, что агрегаты магнитных коллоидных частиц оксидов железа имеют фрактальную структуру и содержат сотни частиц. В [7] был сделан вывод о том, что в результате протекания жидкости через УМО происходит дробление фрактальных агрегатов магнитных частиц, что приводит к росту концентрации центров кристаллизации, роль которых играют отдельные магнитные коллоидные частицы железа и их кластеры.

При исследовании концентрации механических примесей с характерными размерами от 5-10 мкм до 100 мкм в воде было 
установлено, что частицы железа служат центрами формирования газовых пузырьков в пересыщенных по воздуху водных растворах. Газовые пузырьки в воде представляют рассевающие линзы и при регистрации интенсивности проходящего света в фотометрическом счетчике механических примесей снижают интенсивность проходящего света, аналогично непрозрачным частицам. После магнитной обработки количество газовых пузырьков, сформированных на частицах железа, выросло более чем, в три раза, после растворения оксидов железа с помощью добавления в раствор специального реагента количество пузырьков уменьшилось более, чем в четыре раза [10]. В [10] был сделан вывод о том, наиболее вероятными примесями в воде и нефти, вызывающими эффект действия УМО, являются игольчатые, однодоменные кристаллы оксидов железа с длиной порядка 300 нм. Произведенная в этой работе оценка величины силы магнитного отталкивания, возникающего при воздействии внешнего магнитного поля, показала, что она достаточна для преодоления силы межмолекулярного притяжения между частицами.

Из предложенного в [10] физико-химического механизма действия УМО следовало, что в составе АСПО должны находиться коллоидные частицы оксидов железа игольчатого типа, которые не были ранее зарегистрированы. Целью данной работы является исследование структуры и состава АСПО для подтверждения роли магнитных частиц железа в формировании отложений.

\section{Экспериментальные результаты и обсуждение}

С целью подтверждения и уточнения предложенной в $[7,10]$ модели для исследования состава АСПО были выбраны образцы отложений со стенок трубопровода месторождения «Белый тигр» (Вьетнам). Нефть месторождения «Белый тигр» содержит большое количество примесей соединений железа; в трещинно-поровом пространстве коллектора 
зарегистрированы частицы соединений железа, образующие, в частности, игольчатые агрегаты [11].

В [12] было исследовано влияние УМО на скорость роста АСПО и вязкость сырой нефти месторождения «Белый тигр». Обработка осуществлялась при течении нефти через трубу, внутри которой создавалось магнитное поле напряженностью от 0,50 до 0,85 Тл. Было обнаружено, что после прохождения через УМО скорость роста АСПО снижалась на десятки процентов, АСПО были менее вязкими, вязкость сырой нефти уменьшалась в несколько раз. Вязкость нефти в покое после MO увеличивалась и за несколько часов достигала исходных значений. Увеличение доли воды в составе нефти сопровождалось снижением скорости роста АСПО после МО, при этом размеры частиц АСПО после МО значительно уменьшались [12].

Результаты работы [12] подтверждали модель [7, 10] влияния УМО на физико-химические свойства нефти, согласно которой МО приводит одновременно как к снижению вязкости, так и к снижению скорости роста АСПО, поскольку оба эффекта обусловлены ростом количества центров кристаллизации - ростом коллоидных частиц нефти [13-15]. Наличие большого количества частиц железа в составе нефти месторождения «Белый тигр» давало основания получить прямые доказательства присутствия коллоидных частиц железа в составе отложений и, таким образом, подтвердить гипотезу о роли магнитных частиц окислов железа в составе АСПО.

Путем применения методов анализа состава нефти, ранее описанных в [!6], было установлено, что неорганическими примесями в АСПО являются суперпарамагнитные, наноразмерные частицы оксидов трехвалентного железа. Определение формы и размеров частиц оксидов железа стало возможным при использовании просвечивающей электронной микроскопии (ПЭМ). 
На рисунке 1 показаны типичные фотографии различных фрагментов АCПО, полученные методом ПЭМ с помощью LEO 912 AB Omega microscope.

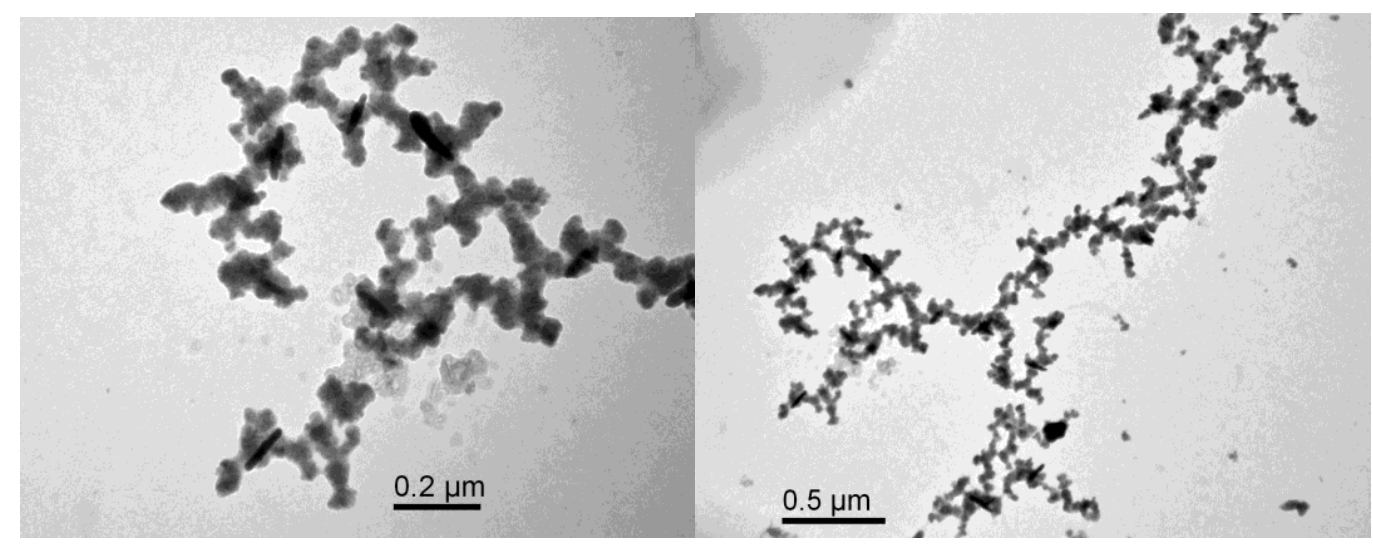

a)

б)

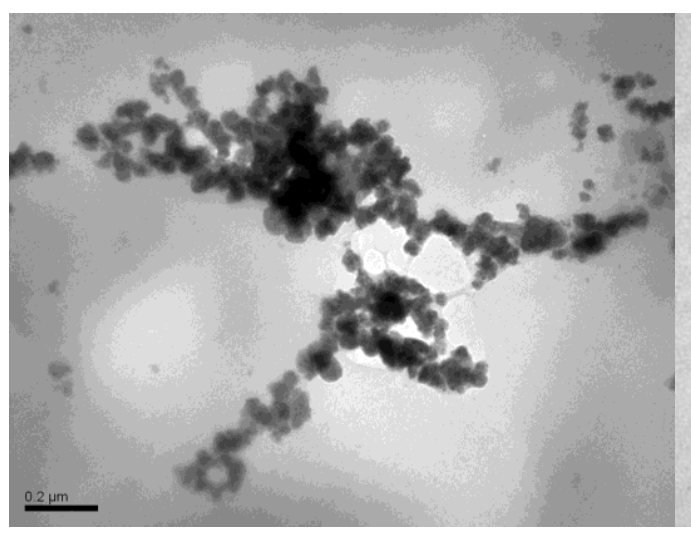

B)

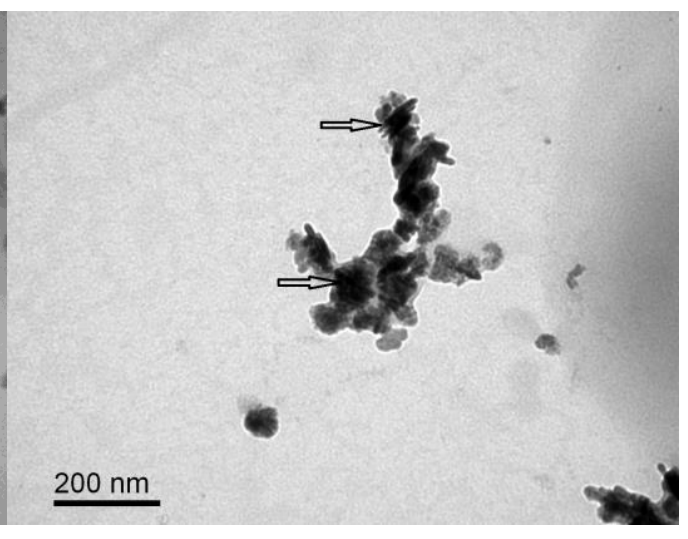

г)

Рисунок 1. Изображения фрагментов АСПО, полученные методом ПЭМ

На рисунке 1 коллоидные частицы нефти округлые, серого цвета, частицы размером $\approx 30-50$ нм, представляют ядра мицелл, образованные углеводородами с давлением насыщенных паров не более $10^{-3}$ мм рт. ст., поскольку измерения происходили в условиях вакуума, что сопровождалась испарением легких углеводородов. Неорганические примеси оксидов железа имеют форму игольчатых частиц; как видно на 
рисунке 1, a) такие частицы находятся внутри скоплений коллоидных частиц нефти.

Коллоидные частицы нефти совместно с частицами железа образуют линейно-цепочечные агрегаты фрактального строения (ФА).

На рисунке $1, a)$ представлена фотография фрагмента ФА, показанного на рисунке 1, б). Линейные размеры ФА составляли 5-7 мкм.

На рисунке 1, в) представлен ФА с ярко выраженным темным ядромцентром роста.

На рисунке 1, г) представлен агрегат, в составе которого находятся расположенные взаимно параллельно, находящиеся в контакте друг с другом частицы оксидов железа, имеющие вид иголок (указаны стрелками). Все частицы оксидов железа находятся внутри коллоидных частиц нефти, что доказывает роль таких частицы в качестве центров формирования отдельных коллоидных частиц и их агрегатов. Линейноцепочечная структура ФА подтверждает гипотезу о каркасном строении АСПО.

Длина игольчатых частиц $\left(\mathrm{Fe}_{3} \mathrm{O}_{4}\right.$ (магнетит) и/или гамма- $\mathrm{Fe}_{2} \mathrm{O}_{3}$ (маггемит)). варьировала в пределах 100-40 нм, диаметры - в пределах 20-10 нм. Спектры ЭМР показали, что присутствующие в составе АСПО оксиды железа обладают свойствами суперпарамагнетиков: малых ферромагнитных частиц, у которых магнитный момент не связан с механическим, т.е. магнитный момент изменяет свое направление без изменения ориентации механического момента.

Преимущество игольчатых частиц оксида железа в качестве адсорбентов компонентов нефти состоит в том, что кривизна поверхности 1/R ( $\mathrm{R}$ - радиус кривизны) вдоль прямой линии - длинной оси кристалла равна нулю. Поэтому для адсорбции на такой поверхности не нужно создавать избыточное давление для преодоления давления поверхностного натяжения $\sigma: \sigma / \mathrm{R}$. 
Регистрация наноразмерных магнитных частиц в виде стержней (иголок) в составе агрегатов коллоидных частиц нефти подтверждает гипотезу [10] о роли таких магнитных частиц в качестве центров кристаллизации твердой фазы углеводородов.

В [12] установлено, что увеличение доли воды в составе нефть - вода сопровождается увеличением защитного эффекта от МО и уменьшением размеров частиц АСПО на поверхности. В [17] было обнаружено, что в составе воды могут присутствовать суперпарамагнитные частицы оксидов железа. Такие частицы в составе воды в составе жидкости могут взаимодействовать с нефтью, увеличивая количество центров кристаллизации - адсорбции асфальтенов. С учетом вышесказанного можно сделать вывод о том, что магнитные частицы могут присутствовать как собственно в нефти, так и попадать в нее из сопутствующей воды.

Поскольку источником центров кристаллизации АСПО являются ФА магнитных частиц железа $[8,9]$, рассмотрим вопрос о механизме разрушения таких агрегатов при МО. Как было отмечено ранее, цель установки МО состоит в максимальном разрушении ФА магнитных частиц на отдельные частицы. Опытным путем при тестировании многочисленных устройств МО было установлено, что существует такая скорость потока $V$, при которой достигается максимальный эффект МО [18]. Установлено, что для достижения максимального эффекта МО необходимо, чтобы:

1. вектор магнитного поля $B$ был перпендикулярен вектору $V$ (скалярное произведение $V \cdot B=0$ );

2. вектор $B$ 2-5 раз изменял свое направление на противоположное;

3. между участками с разным направлением магнитного поля находились участки с высоким градиентом магнитного поля $d B / d r$ $(r-$ расстояние от оси трубопровода).

Ниже приведен анализ магнитных и гидродинамических сил, действующих на ФА, образованный игольчатыми, суперпарамагнитными 
частицами оксидов железа, - именно такая топология магнитного поля может обеспечить полное разрушение ФА и получение магнитных частиц, отделенных друг от друга на расстояния, при которых можно пренебречь их магнитным притяжением.

При течении жидкости в трубе возникает градиент скорости потока $d V / d r$, создающий вращающий момент сил вязкого трения $M_{f} \sim d V / d r$. Здесь в качестве характерного размера присутствует максимальный размер частицы 1.

В магнитном поле на частицу $m$ действует момент сил $M_{m}=[m B]$ ([mB] - векторное произведение; $m$ - магнитный момент). Под действием $M_{m}$ частицы вращаются так, чтобы $m$ стал параллельным вектору $B$. Кроме того, на частицы действует сила $F_{m}$, вызывающая движение в область с высоким градиентом магнитного поля $d B / d r-F_{m}=\operatorname{grad}(m \cdot B)$, где $m B-$ скалярное произведение векторов $m$ и $B$.

Рассмотрим действие этих сил на наиболее прочно связанную пару магнитных частиц, находящихся на расстоянии максимального сближения. Оценка сил магнитного притяжения/отталкивания между частицами $F a$ может быть оценена с помощью формулы: $F a \approx 3\left(m^{2} / d^{4}\right)$, где $d$ - диаметр частицы, имеющей форму иглы длиной 1. Для противоположно направленных магнитных моментов (магнитных диполей) $m$ возникает сила магнитного притяжения, при одинаковом направлении возникает сила магнитного отталкивания, поскольку одноименные магнитные полюса оказываются наиболее близко друг к другу. Первоначально, в отсутствие магнитного поля, энергетически выгодной является ситуация антипараллельной ориентации $m$, но под действием достаточно сильного магнитного поля $B$ магнитные моменты становятся параллельными, и сила магнитного притяжения сменяется на силу отталкивания.

В работе [10] была произведена оценка силы магнитного отталкивания для ферромагнитных частиц магнетита длиной 300 нм и диаметром 50 нм, представляющих одиночные магнитные домены с осью легкой 
намагниченности в направлении длинной оси частицы. Для частиц магнетита была также сделана оценка сил дисперсионного электрического притяжения $F_{e l}$. Для таких частиц оценки показали, что $F_{e l} \approx 3 \cdot 10^{-5}$ дин, а $F_{a} \approx 310^{-3}$ дин. Поскольку обе силы пропорциональны объему частиц, то соотношение $F_{a}>F_{e l}$ будет сохраняться и при изменении размеров частиц.

Полученная оценка показывает, что при движении ФА вместе с потоком жидкости в сильном магнитном поле $B$ между частицами возникают силы отталкивания, которые приводят к дроблению ФА. Изменение направления магнитного момента $m$ суперпарамагнитной частицы не связано с механическим вращением, происходит за доли секунды, обеспечивает взаимное отталкивание частиц и дробление ФА в однородном магнитном поле. На вращение частиц воздействует помимо магнитного поля течение жидкости, создающее момент сил $M_{f} \sim l d V / d r$, также вызывающих вращение. Время, необходимое для изменения взаимной ориентации частиц, зависит от напряженности поля $B$, поэтому область, занятая полем, должна зависеть от скорости движения потока.

Для препятствия восстановлению ФА необходимо разделить пространственно магнитные частицы на такие расстояния, при которых силы их взаимного притяжения будут близки к нулю. Поэтому процесс разрушения ФА продолжается в зоне неоднородного магнитного поля, где частицы, вращаясь, движутся под действием неоднородного магнитного поля с различными ускорениями, обусловленными дисперсией величин магнитных моментов. Чрезмерно большие градиенты магнитного поля могут вызвать остановку магнитных частиц больших размеров в этой области, если силы вязкого трения будут недостаточны для выноса таких частиц.

Как следует из вышеприведенного анализа, одновременное разрушающее действие магнитных сил и сил вязкого трения имеет сложный характер, зависящий от скорости потока при данном распределении магнитного поля в устройстве МО, поэтому эффективность 
разрушения ФА конкретным УМО зависит от скорости протекания жидкости и от физико-химических свойств примесей ФА.

Возникновение сил отталкивания вызывает понижение давления в пространстве между частицами, что приводит к возникновению газовых пузырей на частицах в условиях начала выделения газа в скважинной жидкости. Такие газовые пузырьки, на которых формируются коллоидные частицы нефти, являются переносчиками частиц АСПО к стенкам НКТ. В [19] при использовании формулы Сегре-Зильберга была произведена оценка скоростей движения пузырьков радиуса $b$ для типичных условий работы добывающих скважин [19]. Согласно формуле скорость радиального движения пузырька $V_{r}$ при ламинарном течении жидкости зависит от скорости потока $V_{ж}$, расстояния от оси трубы $r$, вязкости жидкости $\eta$ и радиуса трубы $r_{t}$ :

$$
V_{r} \sim V_{\text {ж⿻ }}\left(r b^{2} / \eta r_{t}^{2}\right)^{0,5}
$$

Оценки времени прохождения газового пузырька от оси к стенке НКТ 73 мм показали, что для $b<20$ мкм это время составляет несколько часов, а для $b>100$ мкм - несколько секунд. Из [19] следует, что МО может за счет увеличения количества пузырьков газа создать устойчивую в объеме взвесь - мелкодисперсную взвесь частиц АСПО и, как следствие, резко сократить скорость роста отложений.

Вероятность закрепиться на стенке НКТ для частицы АСПО зависит от соотношения сил притяжения к поверхности $F_{c}$ и сил вязкого трения $b^{2} \eta(V / d r)$. В [1] было установлено, что частицы АСПО обладают положительным зарядом. Поскольку в кислой среде оксиды железа приобретают положительный заряд, естественно предположить, что он определяется суммарным зарядом частиц оксидов железа в частице АСПО.

Следовательно,

$$
F_{c}=q^{2} / \varepsilon(2 h)^{2}+K h^{2}
$$

где $q$ - заряд; 
$\varepsilon$ - диэлектрическая проницаемость среды;

$h$ - радиус частицы АСПО;

$K h^{2}$ - адсорбционные силы, пропорциональные площади контакта частицы АСПО с металлом НКТ.

Согласно предложенному в $[10,18]$ механизму МO увеличение концентрации коллоидных частиц железа приводит к уменьшению размеров частиц АСПО, как и наблюдалось в [12], что приводит к снижению силы $F_{c}$, а поскольку радиус газового пузырька $b>h$, то при уменьшении $h$ снижается вероятность прикрепления частицы АСПО на поверхности.

Согласно [20] электростатическое притяжение играет значительную роль в процессе закрепления частиц АСПО и последующего роста отложений, поэтому увеличение расстояния $h$ между зарядом и поверхностью путем покрытия внутренней, шероховатой, поверхности НКТ стеклом резко снижает скорость роста отложений.

Использование MO на работающих скважинах позволяет не только снизить скорость роста АСПО, но и удалять уже имеющиеся отложения благодаря процессу захвата частиц АСПО газовыми пузырьками, сформированными на поверхности магнитных частиц железа. Высокая эффективность устройств для МО, разработанных с учетом описанных выше процессов взаимодействия ФА с магнитным полем [21, 22], показала правильность физико-химического механизма МО [23-25].

Исследования последних лет показали, что введение извне магнитных коллоидных частиц оксидов железа приводит как к снижению вязкости, так и к снижению скорости роста АСПО [26, 27]. Эти исследования подтверждают, что первичным результатом MO является рост концентрации частиц железа.

Теория воздействия магнитного поля на скорость роста АСПО позволяет предложить простые методы определения целесообразности 
применения устройств для МО в условиях конкретной скважины и трубопровода.

Одним из таких методов является выделение твердых неорганических частиц путем осаждения асфальтенов с последующей промывкой растворителем и исследованием магнитных свойств осадка. Поскольку МО вызывает разрушение эмульсий нефть - вода, то рост количества отделившейся воды после МО также можно установить в местной лаборатории. МО вызывает резкое газовыделение, поэтому резкое вскипание сырой нефти, отобранной из промыслового нефтепровода, говорит о перспективности использования УМО.

\section{Выводы}

Регистрация в составе АСПО коллоидных магнитных частиц оксидов железа игольчатой формы подтверждает ранее предложенный физикохимический механизм защиты трубопроводов от отложений при использовании магнитной обработки нефти. Структура фрактальных агрегатов коллоидных частиц нефти в АСПО соответствует каркасному строению отложений.

Работа выполнена в соответствии с планом РАН «Исследование термодинамических свойств углеводородных смесей, моделирование гидротермодинамических и геомеханических процессов в геосредах с изелью повышения эффективности трудноизвлекаемых запасов нефти и газа».

\section{Список используемых источников}

1. Бабалян Г.А. Борьба с отложениями парафина. М.: Недра, 1965. $340 \mathrm{c}$.

2. Галеев Р.Г., Дияшев Р.Н., Потапов С.С. Исследование минерального состава и причин отложений солей в нефтепромысловом оборудовании // Нефтяное хозяйство. 1998. № 5. С. 41-45. 
3. Pfeiffer J.Ph., Saal R.N.J. Asphaltic Bitumen as Colloid System // The Journal of Physical Chemistry. 1940. Vol. 44. P. 139-149.

4. Rahmani N.H.G., Tabros T., Masliyah Y.H. Fractal Structure of Asphaltene Aggregates // Journal of Colloid and Interface Science. 2005. Vol. 285. Issue 2. P. 599-608. DOI: 10.1016/j.jcis.2004.11.068.

5. Лютоев А.А., Смирнов Ю.Г. Разработка технологической схемы очистки сточных вод от нефтяных загрязнений с использованием магнитных наночастиц // Электронный научный журнал «Нефтегазовое дело». 2013. № 4. С. 424-435. URL: http://ogbus.ru/files/ogbus/ authors/LyutoevAA/LyutoevAA_1.pdf (дата обращения: 02.02.2019).

6. Nassar N.N. Iron Oxide Nanoadsorbents for Removal of Various Pollutants from Wastewater: An Overview // Application of Adsorbents for Water Pollution Control. 2012. P. 81-118. DOI: 10.2174/9781 6080526911120101.

7. Лесин В.И., Дюнин А.Г., Хавкин А.Я. Изменение физикохимических свойств водных растворов под влиянием электромагнитного поля // Журнал физической химии. 1993. Т. 67. № 7. С. 1561-1562.

8. Pastor-Satorras R., Rubi J.M. Fractal Properties of Cluster of Colloidal Magnetic Particles // Progress in Colloid and Polymer Science. 1998. Vol. 110. P. 29-33.

9. Brunner R., Gall S., Wilke W., Zrinyi M. Formation of Fractal Structures by Aggregation of Anisometric Iron (III) Hydroxide Particles // Physica A: Statistical Mechanics and its Applications. 1995. Vol. 214. P. 153-161. DOI: 10.1016/0378-4371(94)00255-R.

10. Лесин В.И. Физико-химический механизм предотвращения парафиноотложений с помощью постоянных магнитных полей // Нефтепромысловое дело. 2001. № 5. С. 21-23. 
11. Старостенко В.И., Лукин А.Е., Цветкова Т.А., Заец Л.Н., Донцов В.В., Савиных Ю.В. Об участии суперглубинных флюидов в нафтидогенезе (по данным изучения уникального нефтяного месторождения Белый Тигр) // Геофизический журнал. 2011. Т. 33. № 4. C. 3-32.

12. Tung N.P., Vinh N.Q. Phong N.T.P., Long B.Q.K., Hung P.V. Perspective for using $\mathrm{Nd}-\mathrm{Fe}-\mathrm{B}$ Magnets as a Tool for the Improvement of the Production and Transportation of Vietnamese Crude Oil with High Paraffin Content // Physica B Condensed Matter. 2003. Vol. 327. P. 443-447. DOI: 10.1016/S0921-4526(02)01788-X.

13. Лесин В.И., Лесин С.В. Анализ способов снижения вязкости неньютоновской нефти на основе фрактальной теории // Сетевое издание «Нефтегазовое дело». 2019. № 6. С. 212-237. URL: http://ogbus.ru/files/ogbus/issues/6_2019/ogbus_6_2019_p212-237.pdf (дата обращения: 03.02.2019). DOI: 10.17122/ogbus-2019-6-212-237.

14. Лесин В.И. Математическая модель вязкости тяжелой нефти, содержащей примеси коллоидных наночастиц оксидов металлов // Сетевое издание «Нефтегазовое дело». 2019. № 2. С. 199-216. URL: http://ogbus.ru/files/ogbus/issues/2_2019/ogbus_2_2019_p199-216.pdf (дата обращения: 03.02.2019). DOI: 10.17122/ogbus-2019-2-199-216.

15. Лесин В.И. Физические основы обработки магнитным полем коллоидных систем, участвующих в процессах добычи, транспортировки и подготовки нефти // Научное сетевое издание «Актуальные проблемы нефти и газа». 2018. Вып. 1 (20). URL: http://oilgasjournal.ru/ issue_20/lesin.html (дата обращения: 04.02.2019). DOI: 10.29222/ipng.207857-12.2018-20.art25.

16. Лесин В.И., Кокшаров Ю.А., Хомутов Г.Б. Магнитные наночастицы в нефти // Нефтехимия. 2010. Т. 50. № 2. С. 114-117. 
17. Lesin V.I., Eremin N.A. Study on Application of Colloidal Particles of Metal Oxides to Increase the Oil Recovery Factor // Materials Science and Engineering: Materials of IOP Conference Series. 2019. Vol. 700. P. 012061. DOI:10.1088/1757-899X/700/1/012061.

18. Мартынова О.И, Гусев Я.Т., Леонтьев Е.А. К вопросу о механизме влияния магнитного поля на водные растворы солей // Успехи физических наук. 1969. Т. 98. № 1. С. 195-199.

19. Лесин В.И. Область наиболее эффективного применения магнитных депарафинизаторов при защите от отложений насосно-компрессорных труб добывающих скважин // Бурение и нефть. 2003. № 1. С. 24-27.

20. Максутов Р.А., Газимов М.Г., Влияние электрических свойств материалов на отложение парафина // Нефтяное хозяйство. 1971. № 7. C. 30-32.

21. Пат. 2169033 РФ, МПК В 01 D 17/06. Устройство для обработки движущихся нефтеводогазовых смесей / В.И. Лесин. 2000107996/12, Заявлено 03.04.2000; Опубл. 20.06.2001. Бюл. 17.

22. Пат. 2098604 РФ, МПК Е 21 В 37/00. Устройство для магнитной обработки жидких сред / В.И. Лесин, И.Р. Василенко. 95121325/03, Заявлено 26.12.1995; Опубл. 10.12.1997.

23. Карпов Б.В., Воробъев В.П., Казаков В.Т., Василенко И.Р., Лесин В.И. Предупреждение парафиноотложений при добыче нефти из скважин в осложненных условиях путем применения магнитных устройств // Нефтепромысловое дело. 1996. № 12. С. 17-18.

24. Лесин В.И., Василенко И.Р., Карпов Б.В., Зотиков В.И., Даулинг Р. Предупреждение АСПО в скважинах путем применения магнитных депарафинизаторов в осложненных условиях // Нефтепромысловое дело. 1997. № 4-5. C. 32-36. 
25. Габдрахманов P.А., Любецкий С.В., Шестернина Н.В., Вороновский В.Р., Лесин В.И., Василенко И.Р. Анализ работы магнитных депарафинизаторов в НГДУ «Лениногорскнефть» АО «Татнефть» // Геология, геофизика и разработка нефтяных и газовых месторождений. 1999. № 10. С. 37-40.

26. Aristizabal-Fontal J.E., Cortes F.B., Franco C.A. Viscosity Reduction of Extra Heavy Crude Oil by Magnetite Nanoparticle-Based Ferrofluids // Adsorption Science and Technology (Special Collection: III Workshop on Adsorption, Catalysis and Porous Materials). 2017. P. 1-23. DOI: $10.1177 / 0263617417704309$.

27. Roal M., Molina D., Correa R. The Effect of a Magnetic Field and Magnetite Nanoparticles on the Electrodeposition of Asphaltenes of a Colombian 21api Oil Sample // Journal of Physics Conference Series. 2019. Vol. 1159. P. 012002. DOI: 10.1088/1742-6596/1159/1/012002.

\section{References}

1. Babalyan G.A. Bor'ba s otlozheniyami parafina [Paraffin Control]. Moscow, Nedra Publ., 1965. 340 p. [in Russian].

2. Galeev R.G., Diyashev R.N., Potapov S.S. Issledovanie mineral'nogo sostava i prichin otlozhenii solei $\mathrm{v}$ neftepromyslovom oborudovanii [Study of Mineral Composition and Causes of Salt Deposits in Oil Field Equipment]. Neftyanoe khozyaistvo - Oil Industry, 1998, No. 5, pp. 41-45. [in Russian].

3. Pfeiffer J.Ph., Saal R.N.J. Asphaltic Bitumen as Colloid System. The Journal of Physical Chemistry, 1940, Vol. 44, pp. 139-149.

4. Rahmani N.H.G., Tabros T., Masliyah Y.H. Fractal Structure of Asphaltene Aggregates. Journal of Colloid and Interface Science, 2005, Vol. 285, Issue 2, pp. 599-608. DOI: 10.1016/j.jcis.2004.11.068. 
5. Lyutoev A.A., Smirnov Yu.G. Razrabotka tekhnologicheskoi skhemy ochistki stochnykh vod ot neftyanykh zagryaznenii s ispol'zovaniem magnitnykh nanochastits [Development of the Technological Scheme of Sewage Treatment from Oil Pollution with the use of Magnetic Nanoparticles]. Elektronnyi nauchnyi zhurnal «Neftegazovoe delo» - Electronic Scientific Journal «Oil and Gas Business», 2013, No. 4, pp. 424-435. URL: http://ogbus.ru/files/ogbus/ authors/LyutoevAA/LyutoevAA_1.pdf (accessed 02.02.2019). [in Russian].

6. Nassar N.N. Iron Oxide Nanoadsorbents for Removal of Various Pollutants from Wastewater: An Overview. Application of Adsorbents for Water Pollution Control, 2012, pp. 81-118. DOI: 10.2174/97816080526911120101.

7. Lesin V.I., Dyunin A.G., Khavkin A.Ya. Izmenenie fizikokhimicheskikh svoistv vodnykh rastvorov pod vliyaniem elektromagnitnogo polya [Change in Physicochemical Properties of Aqueous Solutions under the Influence of an Electromagnetic Field]. Zhurnal fizicheskoi khimii - Russian Journal of Physical Chemistry, 1993, Vol. 67, No. 7, pp. 1561-1562. [in Russian].

8. Pastor-Satorras R., Rubi J.M. Fractal Properties of Cluster of Colloidal Magnetic Particles. Progress in Colloid and Polymer Science, 1998, Vol. 110, pp. 29-33.

9. Brunner R., Gall S., Wilke W., Zrinyi M. Formation of Fractal Structures by Aggregation of Anisometric Iron (III) Hydroxide Particles. Physica A: Statistical Mechanics and its Applications, 1995, Vol. 214, pp. 153-161. DOI: 10.1016/0378-4371(94)00255-R.

10. Lesin V.I. Fiziko-khimicheskii mekhanizm predotvrashcheniya parafinootlozhenii s pomoshch'yu postoyannykh magnitnykh polei [PhysicoChemical Mechanism for the Prevention of Paraffin Deposits Using Constant Magnetic Fields]. Neftepromyslovoe delo - Oilfield Engineering, 2001, No. 5, pp. 21-23. [in Russian]. 
11. Starostenko V.I., Lukin A.E., Tsvetkova T.A., Zaets L.N., Dontsov V.V., Savinykh $\mathrm{Yu} . \mathrm{V}$. Ob uchastii superglubinnykh flyuidov $\mathrm{v}$ naftidogeneze (po dannym izucheniya unikal'nogo neftyanogo mestorozhdeniya Belyi Tigr) [On the Participation of Super-Deep Fluids in Naphthyogenesis (According to the Study of the Unique Oil Deposit of the White Tiger)]. Geofizicheskii zhurnalGeophysical Journal, 2011, Vol. 33, No. 4, pp. 3-32. [in Russian].

12. Tung N.P., Vinh N.Q. Phong N.T.P., Long B.Q.K., Hung P.V. Perspective for Using $\mathrm{Nd}-\mathrm{Fe}-\mathrm{B}$ Magnets as a Tool for the Improvement of the Production and Transportation of Vietnamese Crude Oil with High Paraffin Content. Physica B Condensed Matter, 2003, Vol. 327, pp. 443-447. DOI: 10.1016/S0921-4526(02)01788-X.

13. Lesin V.I., Lesin S.V. Analiz sposobov snizheniya vyazkosti nen'yutonovskoi nefti na osnove fraktal'noi teorii [Analysis of Ways to Reduce Non-Newtonian Oil Viscosity Based on Fractal Theory]. Setevoe izdanie «Neftegazovoe delo»-Online Edition «Oil and Gas Business», 2019, No. 6, pp. 212-237. URL: http://ogbus.ru/files/ogbus/issues/6_2019/ogbus_6_2019_ p212-237.pdf (accessed 03.02.2019). DOI: 10.17122/ogbus-2019-6-212-237. [in Russian].

14. Lesin V.I. Matematicheskaya model' vyazkosti tyazheloi nefti, soderzhashchei primesi kolloidnykh nanochastits oksidov metallov [Viscosity Mathematical Model of Heavy Oil Containing the Metal Oxides Colloid Nanoparticles Impurity]. Setevoe izdanie «Neftegazovoe delo» - Online Edition «Oil and Gas Business», 2019, No. 2, pp. 199-216. URL: http://ogbus.ru/files/ogbus/issues/2_2019/ogbus_2_2019_p199-216.pdf (accessed 03.02.2019). DOI: 10.17122/ogbus-2019-2-199-216. [in Russian]. 
15. Lesin V.I. Fizicheskie osnovy obrabotki magnitnym polem kolloidnykh sistem, uchastvuyushchikh $\mathrm{v}$ protsessakh dobychi, transportirovki i podgotovki nefti [Physical Basis of Magnetic Field Treatment of Colloidal Systems Involved in Oil and Gas Industry Processes]. Nauchnoe setevoe izdanie «Aktual'nye problemy nefti i gaza» - Actual Problems of Oil and Gas, 2018, Issue 1 (20). Available at: http://oilgasjournal.ru/issue_20/lesin.html (accessed 04.02.2019). DOI: 10.29222/ipng.2078-57-12.2018-20.art25. [in Russian].

16. Lesin V.I., Koksharov Yu.A., Khomutov G.B. Magnitnye nanochastitsy $\mathrm{v}$ nefti [Magnetic Nanoparticles in Petroleum]. Neftekhimiya - Petroleum Chemistry, 2010, Vol. 50, No. 2, pp. 114-117. [in Russian].

17. Lesin V.I., Eremin N.A. Study on Application of Colloidal Particles of Metal Oxides to Increase the Oil Recovery Factor. Materials of IOP Conference Series «Materials Science and Engineering». 2019, Vol. 700, pp. 012061. DOI:10.1088/1757-899X/700/1/012061.

18. Martynova O.I, Gusev Ya.T., Leontev E.A. K voprosu o mekhanizme vliyaniya magnitnogo polya na vodnye rastvory solei [To the Question of the Mechanism of the Influence of a Magnetic Field on Aqueous Solutions of Salts]. Uspekhi fizicheskikh nauk - Uspekhi Fizicheskikh Nauk, 1969, Vol. 98, No. 1, pp. 195-199. [in Russian].

19. Lesin V.I. Oblast' naibolee effektivnogo primeneniya magnitnykh deparafinizatorov pri zashchite ot otlozhenii nasosno-kompressornykh trub dobyvayushchikh skvazhin [The Area of the Most Effective use of Magnetic Dewaxing in the Protection against Deposits of Tubing of Producing Wells]. Burenie i neft' - Drilling and Oil, 2003, No. 1, pp. 24-27. [in Russian].

20. Maksutov R.A., Gazimov M.G., Vliyanie elektricheskikh svoistv materialov na otlozhenie parafina [Effect of Electrical Properties of Materials on Paraffin Deposition]. Neftyanoe khozyaistvo - Oil Industry, 1971, No. 7, pp. 3032. [in Russian]. 
21. Lesin V.I. Ustroistvo dlya obrabotki dvizhushchikhsya neftevodogazovykh smesei [Device for Processing Moving Oil and Gas Mixtures]. Patent RF, No. 2169033, 2001. [in Russian].

22. Lesin V.I., Vasilenko I.R. Ustroistvo dlya magnitnoi obrabotki zhidkikh sred [Device for Magnetic Processing of Liquid Media]. Patent RF, No. 2098604, 1997. [in Russian].

23. Karpov B.V., Vorobev V.P., Kazakov V.T., Vasilenko I.R., Lesin V.I. Preduprezhdenie parafinootlozhenii pri dobyche nefti iz skvazhin $\mathrm{V}$ oslozhnennykh usloviyakh putem primeneniya magnitnykh ustroistv [Prevention of Paraffin Deposits during Oil Production from Wells in Complicated Conditions by Using Magnetic Devices]. Neftepromyslovoe delo - Oilfield Engineering, 1996, No. 12, pp. 17-18. [in Russian].

24. Lesin V.I., Vasilenko I.R., Karpov B.V., Zotikov V.I., Dauling R. Preduprezhdenie ASPO v skvazhinakh putem primeneniya magnitnykh deparafinizatorov v oslozhnennykh usloviyakh [Prevention of Paraffin in Wells by Using Magnetic Dewaxing in Difficult Conditions]. Neftepromyslovoe deloOilfield Engineering, 1997, No. 4-5, pp. 32-36. [in Russian].

25. Gabdrakhmanov R.A., Lyubetskii S.V., Shesternina N.V., Voronovskii V.R., Lesin V.I., Vasilenko I.R. Analiz raboty magnitnykh deparafinizatorov v NGDU «Leninogorskneft'»AO «Tatneft'» [Analysis of the Work of Magnetic Dewaxing in NGDU "Leninogorskneft" JSC "Tatneft"]. Geologiya, geofizika $i$ razrabotka neftyanykh $i$ gazovykh mestorozhdenii Geology, Geophysics and Development of Oil and Gas Fields, 1999, No. 10, pp. 37-40. [in Russian].

26. Aristizabal-Fontal J.E., Cortes F.B., Franco C.A. Viscosity Reduction of Extra Heavy Crude Oil by Magnetite Nanoparticle-Based Ferrofluids. Adsorption Science and Technology (Special Collection: III Workshop on Adsorption, Catalysis and Porous Materials). 2017. pp. 1-23. DOI: 10.1177/0263617417704309. 
27. Roal M., Molina D., Correa R. The Effect of a Magnetic Field and Magnetite Nanoparticles on the Electrodeposition of Asphaltenes of a Colombian 21api Oil Sample. Journal of Physics Conference Series, 2019, Vol. 1159, pp. 012002. DOI: 10.1088/1742-6596/1159/1/012002.

\section{Сведения об авторе}

\section{About the author}

Лесин Виктор Иванович, канд. физ.-мат. наук, ведущий научный сотрудник, Институт проблем нефти и газа Российской Академии наук (ИПНГ РАН), г. Москва, Российская Федерация

Viktor I. Lesin, Candidate of Physical and Mathematical Sciences, Leading Researcher, Oil and Gas Research Institute of Russian Academy of Sciences, Moscow, Russian Federation

e-mail: vilesin@inbox.ru 